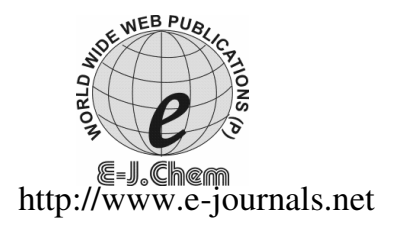

ISSN: 0973-4945; CODEN ECJHAO

E-Journal of Chemistry 2011, 8(1), 127-130

\title{
Electrical Conductivity Properties of Newly Synthesized Melamine - Aniline - Formaldehyde Terpolymer and its Polychelates
}

\author{
K. P. DHARKAR ${ }^{*}$, S.S.INGLE and A.B. KALAMBE \\ Department of Chemistry \\ Institute of Science, Nagpur-440 010, India \\ kpdharkar@rediffmail.com
}

Received 24 May 2010; Accepted 15 July 2010

\begin{abstract}
Terpolymer MAF synthesized by the polycondensation of melamine (M) and aniline (A) with formaldehyde (F) in the presence of an acid catalyst in 1:1:3 molar proportions of the reacting monomers. Polychelates were prepared by using metal acetate, metal salts and MAF ligand in DMF medium. The prepared terpolymer and its polychelates were characterized by using elemental analysis, magnetic studies and spectral analysis. In the present paper, electrical conductivity properties of the terpolymer and its polychelates were studied over a wide range of temperature and is in the order MAF $<\mathrm{Mn}$ (II) $<\mathrm{Fe}$ (III) and $<\mathrm{Co}$ (II). The activation energy of terpolymer and its polychelates were evaluated from the plots of $\log \sigma$ versus $1 / \mathrm{T}$. Activation energy values lie in the range of $0.847 \mathrm{eV}$ to $1.156 \mathrm{eV}$. On the basis of electrical conductivity measurements of terpolymer and its polychelates, it was found that, at higher temperature conductivity increases linearly, showing semi conducting behaviour and hence useful in electronic industry.
\end{abstract}

Keywords: Electrical conductivity, Terpolymer, Activation energy, Chelate Polymer, Polychelate, Semiconductor

\section{Introduction}

Semiconductors have played an extremely vital role in the development of modern electronics; particularly in the communication and computer fields. It is because of the only software, which has made it possible to microminiaturise massive electronic gadgets. The electrical conduction mechanism of the organic semiconductors and especially of the polymers is very important for the application of these materials in electronics, electro techniques and power sources. In this connection, studies were made to establish a correlation 
between the chemical structure and characteristics defining semi-conducting properties ${ }^{1}$. Semiconducting behavior was systematically developed by Brattain et al. ${ }^{2}$. Masram et. $a l^{3}$ reported the synthesis and electrical properties of some resins. Semiconducting behaviour of polymeric ligand and its coordination polymer have been studied by electrical conductivity measurements at different temperatures ${ }^{4}$. Patel ${ }^{5}$ have measured the electrical resistivity of 2,4-dihydroxyactephenone-urea-formaldehyde polymeric ligand and its polychelates over a wide temperature range. They have observed the exponential variation of electrical conductivity with the absolute temperature. Industrial important semiconducting material has been reported by Kanda and Kawaguchi ${ }^{6}$. Electrical conductivity studies on Co(II), $\mathrm{Cu}(\mathrm{II}), \mathrm{Ni}(\mathrm{II})$ and $\mathrm{Cd}(\mathrm{II})$ complexes of azines reported by Revanasiddappa et $_{\text {al }}{ }^{7}$ showing semi conducting behaviour of polymer. The DC charging / discharging currents and electrical conductivity of semi crystalline polymer have been studied by Motori et al. ${ }^{8}$ as a function of temperature and time of applied voltage. The DC electrical conductivity of polydithio-oxamide-metal complexes were studied by Ali El Shekeli et al ${ }^{9}$. In view of above discussion, the present study deals with electrical conductivities of MAF terpolymer and its polychelates with $\mathrm{Mn}(\mathrm{II}), \mathrm{Fe}(\mathrm{III})$ and $\mathrm{Co}(\mathrm{II})$ ions over a wide range of temperature.

\section{Experimental}

All the chemicals used were of analytical reagent grade. DMF was used after distillation.

\section{Synthesis of terpolymer}

Synthesis of terpolymer was carried out by acid-catalyzed polycondensation method ${ }^{10,11}$. A mixture of melamine $(0.05 \mathrm{~mol})$, aniline $(0.05 \mathrm{~mol})$, formaldehyde $(0.15 \mathrm{~mol})$ in $200 \mathrm{~mL}$ $\mathrm{HCl}(2 \mathrm{M})$ was refluxed on oil bath for $6 \mathrm{~h}$ with occasional shaking. The temperature of electrically heated oil bath was controlled with the help of dimmerstat. The resinous solid product obtained was immediately removed from the flask as soon as the reaction period was over. It was then purified by dissolving in $(1 \mathrm{M})$ sodium hydroxide solution, filtered and re-precipitated by gradual drop wise addition of ice cold $(2 \mathrm{M}) \mathrm{HCl}$ with constant and rapid stirring to avoid lump formation. The MAF terpolymer so obtained was filtered, washed several times with hot water, dried in air, powdered and kept in vacuum desiccators over silica gel ${ }^{12,13}$. The detailed analytical data of terpolymer MAF is tabulated in Table 1.

Table 1. Analytical data of terpolymer MAF

\begin{tabular}{ccccccc}
\hline Terpolymer & $\begin{array}{c}\text { Carbon \% } \\
\text { Found } \\
\text { (calcd.) }\end{array}$ & $\begin{array}{c}\text { Hydrogen \% } \\
\text { Found } \\
\text { (calcd.) }\end{array}$ & $\begin{array}{c}\text { Nitrogen \% } \\
\text { Found } \\
\text { (calcd.) }\end{array}$ & $\begin{array}{c}\text { Yield } \\
\%\end{array}$ & $\begin{array}{c}\text { m.p } \\
\text { K }\end{array}$ & $\begin{array}{c}\text { Empirical } \\
\text { formula } \\
\text { weight }\end{array}$ \\
\hline$[\mathrm{MAF}]_{\mathrm{n}}$ & $55.81(56.03)$ & $5.81(5.84)$ & $37.98(38.13)$ & 79 & 563 & 257 \\
\hline
\end{tabular}

\section{Synthesis of polychelates}

Terpolymer and metals as $\mathrm{Mn}$ (II) nitrate, Fe(III) chloride and Co(II) sulphate, solutions were prepared in dimethyl formamide separately. Both the solutions were filtered, mixed in hot condition and refluxed on oil bath for 5-6 $\mathrm{h}$. The polychelates were separated out on addition of saturated solution of sodium acetate. It was then digested for $30 \mathrm{~min}$. to $1 \mathrm{~h}$ on a water bath, filtered; the solid ${ }^{14,15}$ washed with DMF and hot distilled water and dried at $60{ }^{\circ} \mathrm{C}$.

\section{Electrical measurement}

Terpolymer and polychelates were thoroughly grounded in agate pestle and mortar separately. It was then pelletalized isostatically in a steel die at 5-6 tons/inch ${ }^{2}$ with the help of a hydraulic press. The pellet thus obtained was hard and crack free. Thin layer of charcoal 
in acetone coating were then applied on both the side of the pellets. The surface continuity of the pellets was then tested by a multimeter. The average diameter of the pellets and their thickness were measured using a vernier caliper and screw gauge respectively. The resistivity of the terpolymer and polychelates were measured in the variable temperature range using digital multi-meter model DT 92080L.

\section{Results and Discussion}

The prepared terpolymer and polychelates were characterized by using various physical methods viz. elemental, magnetic susceptibility, IR, NMR and UV-Visible. All these data reveals that the formation of metal complexes through the donor sites of $\mathrm{N}$-atom ${ }^{16-18}$.

The values of electrical conductivity $(\sigma)$ were obtained from the resistively values $(\sigma=1 / \rho)$. The electrical conductivity varies exponentially with the absolute temperature according to the well known relationship

$$
\sigma=\sigma_{0} \exp .\left(-E_{a} / K T\right)
$$

Where, $\sigma=$ Electrical conductivity at temperature $\mathrm{T}$

$\sigma_{0}=$ Electrical conductivity at temperature $\mathrm{T} \rightarrow \infty$ i.e., constant.

$\mathrm{E}_{\mathrm{a}}=$ Activation energy of electrical conduction

$\mathrm{K}=$ Boltzmann constant $\left(8.6173 \times 10^{-5} \mathrm{eV} / \mathrm{K}\right)$

$\mathrm{T}=$ Absolute temperature

The above relationship has been modified as,

$$
\log \sigma=\log \sigma_{0}+\left(-E_{a} / 2.303 K T\right)
$$

The temperature dependence of the electrical conductivity of MAF terpolymer and its polychelates is shown in Figure 1.

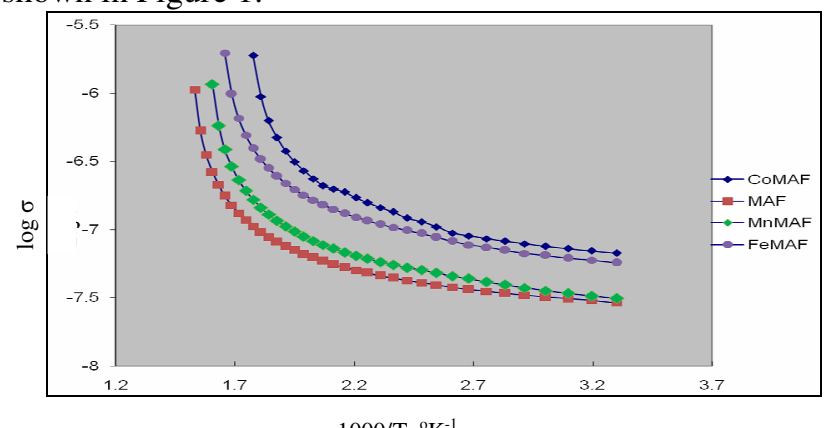

Figure 1. Temperature dependence of the electrical conductivity of MAF terpolymer and its polychelates

Plots of $\log \sigma$ versus $1 / \mathrm{T}$ found to be linear with negative slope. The detailed relevant data on electrical conductivities and activation energies of the terpolymer and polychelates were compiled in Table 2.

Table 2. Electrical conductivities and activation energies of terpolymer and its polychelates

\begin{tabular}{cccc}
\hline $\begin{array}{c}\text { Terpolymer/ } \\
\text { Polychelates }\end{array}$ & $\begin{array}{c}\text { Temperature, } \\
\mathrm{K}\end{array}$ & $\begin{array}{c}\text { Activation } \\
\text { Energy, eV }\end{array}$ & $\begin{array}{c}\text { Electrical Conductance } \\
(\Omega / \mathrm{cm})^{-1}\end{array}$ \\
\hline$[\mathrm{MAF}]_{\mathrm{n}}$ & $303-653$ & 1.15601 & $2.89 \mathrm{E}-08$ \\
{$[\mathrm{MnMAF}]_{\mathrm{n}}$} & $303-623$ & 1.04765 & $3.13 \mathrm{E}-08$ \\
{$[\mathrm{FeMAF}]_{\mathrm{n}}$} & $303-603$ & 0.97839 & $5.71 \mathrm{E}-08$ \\
{$[\mathrm{CoMAF}]_{\mathrm{n}}$} & $303-563$ & 0.84701 & $6.73 \mathrm{E}-08$ \\
\hline
\end{tabular}




\section{Conclusions}

From the results of temperature dependence of electrical conductivity of terpolymer (MAF) and its polychelates following conclusions can be drawn

i) The temperature dependence of electrical conductivity of terpolymer and polychelates exhibits two distinct regions (Figure 1). In low temperature region slope of plots have small values. This may be due to extrinsic conduction present in these polymers. However, in the high temperature region a linear dependence with high values $(\ln \sigma)=\mathrm{f}\left(10^{3} / \mathrm{T}\right)$ was observed with higher values of slopes. This may be due to intrinsic conduction present in these polymers.

ii) At room temperature, terpolymer (MAF) has an electrical conductivity $2.8936 \times 10^{-8}$ $(\mathrm{ohm} \mathrm{cm})^{-1}$.

iii) The electrical conductivity of polychelates of MAF at room temperature lies in the range of $3.1277 \times 10^{-8}(\mathrm{ohm} \mathrm{cm})^{-1}$ to $6.7302 \times 10^{-8}(\mathrm{ohm} \mathrm{cm})^{-1}$.

iii) The electrical conductivity of MAF and its polychelates increases in the order MAF $<\mathrm{Mn}$ (II) $<\mathrm{Fe}$ (III) $<\mathrm{Co}$ (II) at room temperature.

iv) The activation energy of electrical conduction of MAF and its polychelates were determined from high temperature portions of curves $(\ln \sigma)=\mathrm{f}\left(10^{3} / \mathrm{T}\right)$. Activation energy values lie in the range of $0.847 \mathrm{eV}$ to $1.156 \mathrm{eV}$ as shown in Table 2. The plots of $\log \sigma$ vs. 1/T were found to be linear (Figure 1) over a wide range of temperature, indicating semiconducting nature of terpolymer and polychelates.

v) The results indicated that the electrical conductivity and the activation energy values of electrical conduction of these polychelates varies with the metal ions, which may be due to the incorporation of different metal ions in the polymeric ligand which increase the ionization tendency.

\section{References}

1. Gautman F and Lyons L E, Organic semiconductors, John Wiley, New York, 1967.

2. Brattain W H and Garrett G G, Bell Sust Tech J., 1955, 34, 129.

3. Masram D T, Kariya K P and Bhave N S, E-Polymers, 2007, 75.

4. Pancholi H B and Patel M M, J Polym Mater, 1996, 13, 261-267.

5. Patel K D and Patel M M, Synth React Inorg Met.-Org Chem., 1993, 23(2), 299-325.

6. Kanda S and Kawaguchi S, J Chem Phys., 1961, 34, 1070.

7. Revanasiddappa M, Khasim S, Raghavendra S C, Basavaraja C, Suresh T and Angadi S D, E-J Chem., 2008, 5(4), 797-801.

8. Motori A, Saccani A and Sisti L, J Appi Polym sci., 2002, 85(11), 2271-2275.

9. Ali El-Shekeil, Khalid M A, Hussein Al-Maydama and Ashour Al-Karbooly, Europian Polymer J., 2001, 37(3), 575-579.

10. Gurnule W B, Rahangadale P K, Kharat R B and Paliwal L J, Prog Crystal Growth Charct Mater, 2002, 45(1-2), 155-160.

11. Hiwase V V, Kalambe A B, Khedkar K M and Deosarkar S D, E-J Chem., 2010, 7(1), 287-294.

12. Pal T K and Kharat R B, Die Angewandte Makromolkulare Chemie., 1989, 55, 173.

13. Pal T K and Kharat R B, Indian J Chem., 1989, 28A(1), 55.

14. Patel M, Patel G C and Pancholi H B, Indian J Chem Soc., 1995, 72, 533-535.

15. Mohod R B, Wasu R V and Aswar A S, J Indian Chem Soc., 2001,78, 34-36.

16. Hankare P P, Naravane S R, Bhuse V M and Delekar S D, Indian J Chem., 2004, 43A, 2578-2581.

17. Roy S M, Juneja H D and Munshi K N, Synth React Inorg Met-Org Chem., 2001, 31(9), 1611-1621.

18. Sheikh H N, Husain A S, Sharma M, Kalostra B L, Indian J Chem., 2004, 43A, 562-565. 


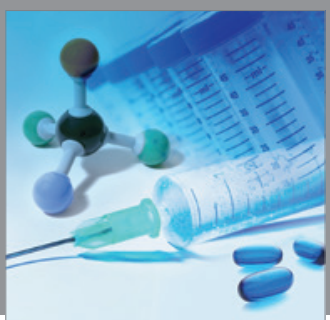

International Journal of

Medicinal Chemistry

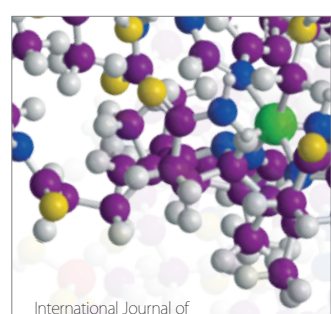

Carbohydrate Chemistry

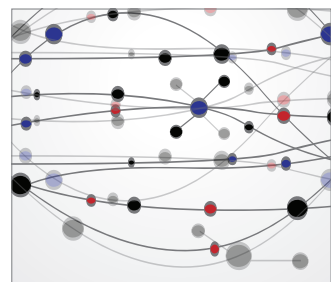

The Scientific World Journal
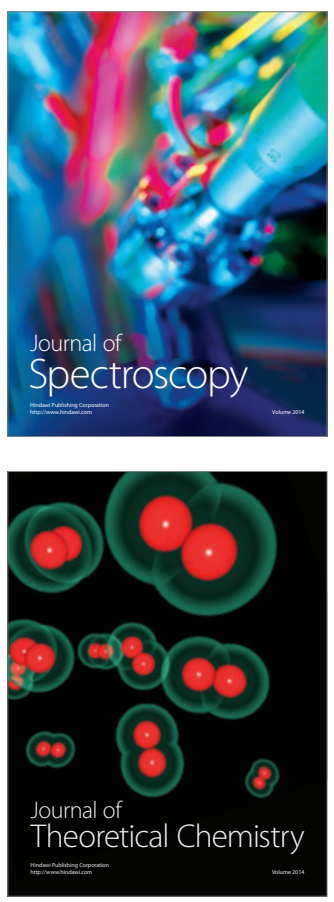
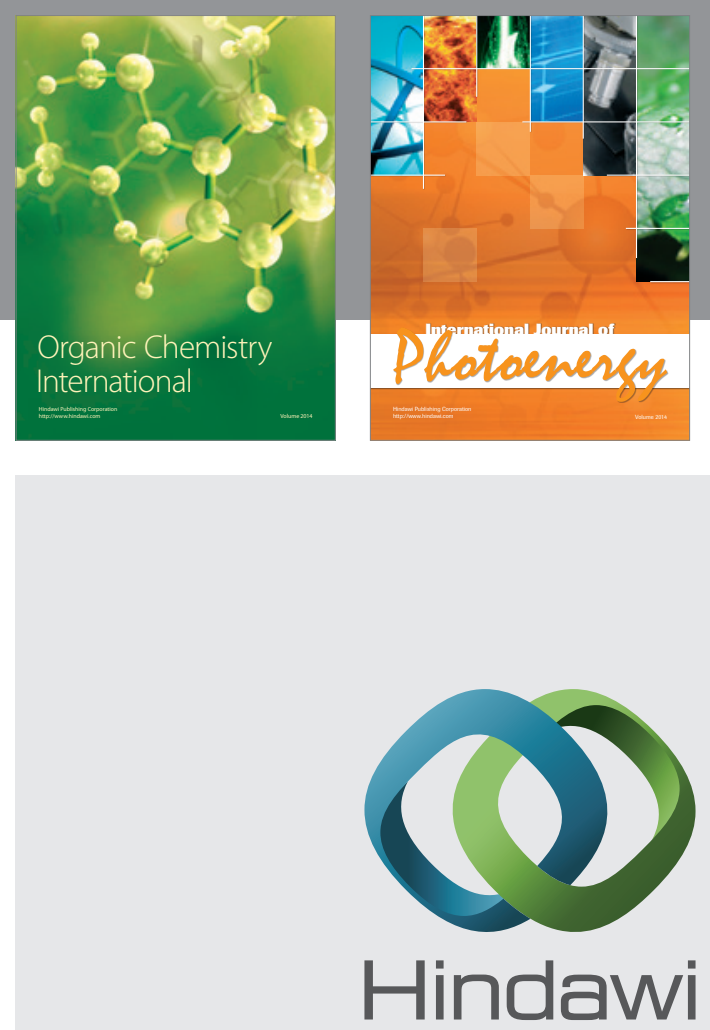

Submit your manuscripts at

http://www.hindawi.com
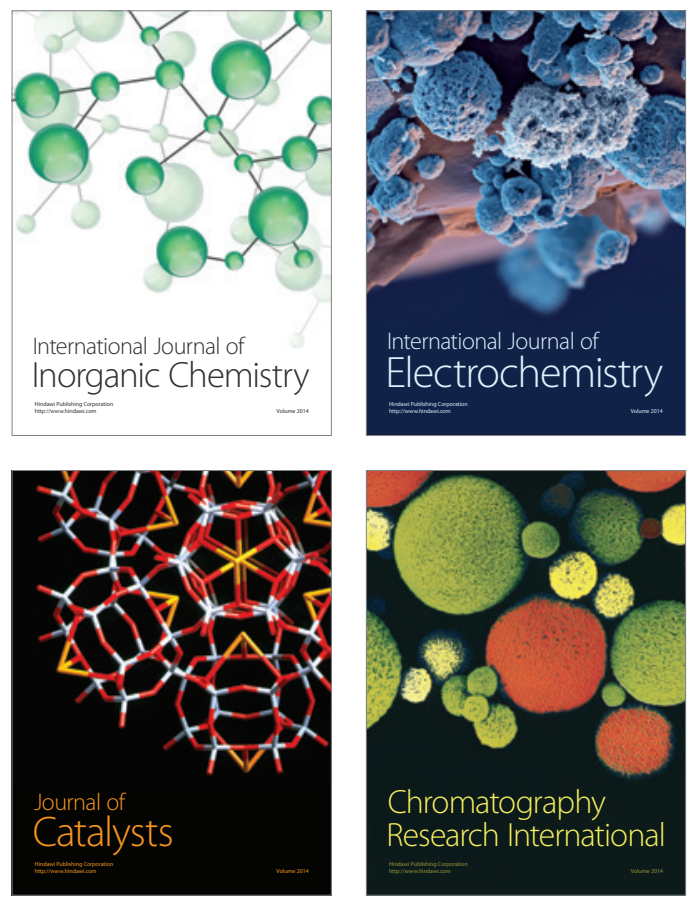
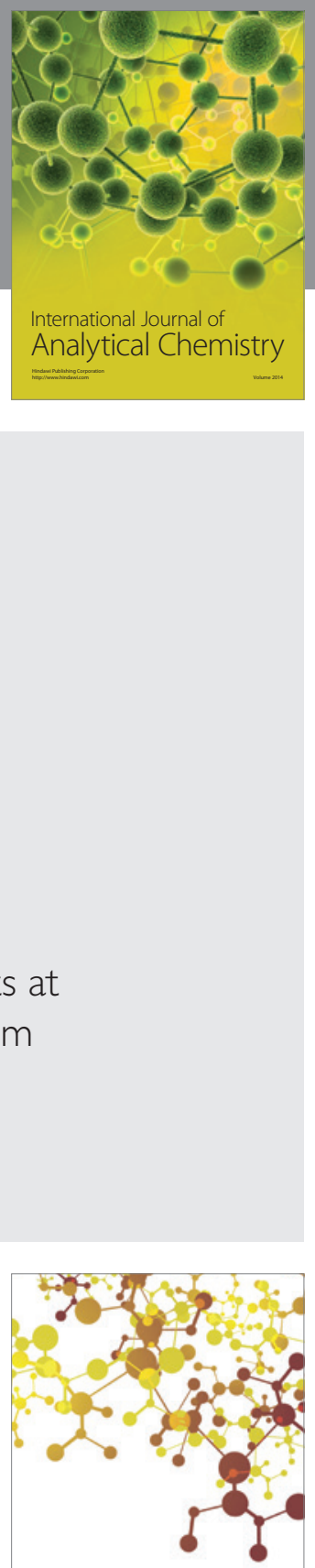

Journal of

Applied Chemistry
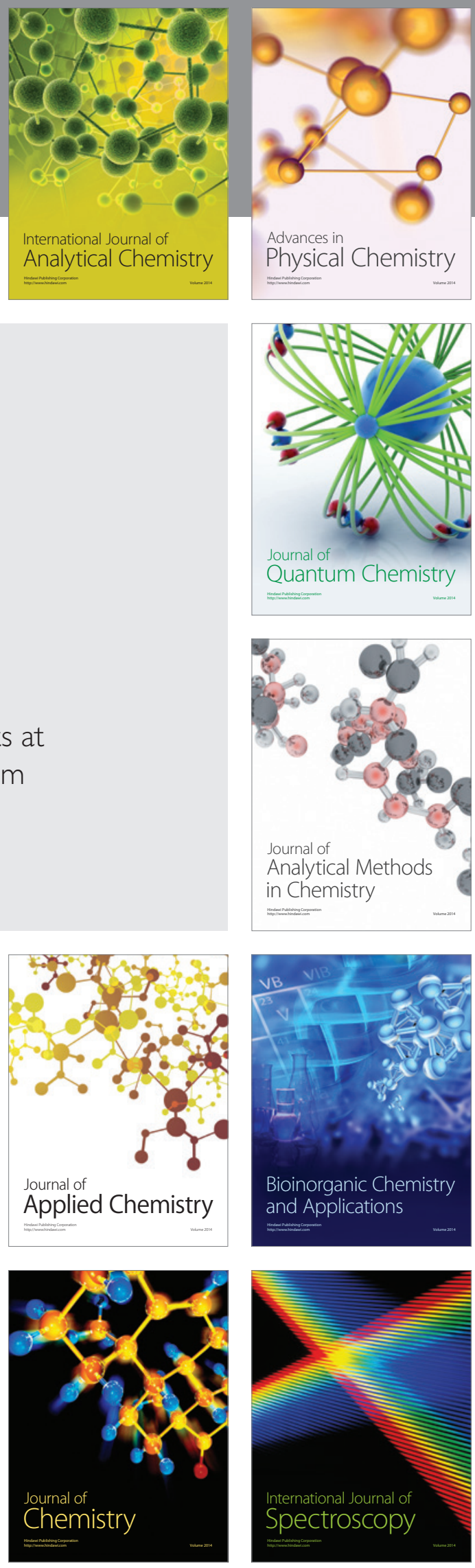